\title{
Research Paper: Health Promoting Self-care Behaviors in Patients With Multiple Sclerosis in the Southeast of Iran: Developing a Model for Practice
}

Victoria Momenabadi $^{1}$ iD, Mohammad Hossein Kaveh ${ }^{1^{*}}$ (D), Nouzar Nakhaee ${ }^{2}$ (D), Kambiz Karimzadeh Shirazi ${ }^{3}$ (D), Behnaz Sedighi² ${ }^{2}$, Seyyed $^{-}$ Hamid Reza Tabatabaei ${ }^{4}$

1. Department of Health Education \& Promotion, School of Health, Shiraz University of Medical Sciences, Shiraz, Iran.

2. Neuroscience Research Center, Kerman University of Medical Sciences, Kerman, Iran.

3. Department of Health Education and Promotion, School of Health and Nutrition Sciences, Yasuj University of Medical Sciences, Yasuj, Iran

4. Department of Epidemiology, Research Center for Health Sciences, School of Health, Shiraz University of Medical Sciences, Shiraz, Iran.

\begin{tabular}{|l|l|}
\hline $\begin{array}{l}\text { Use vour device to san } \\
\text { and read the artice online }\end{array}$ & $\begin{array}{l}\text { Citation: Momenabadi, V., Kaveh, M. H., Nakhaee, N., Karimzadeh Shirazi, K., Sedighi, B., \& Tabatabaei, S. H. R. (2020). } \\
\text { Health Promoting Self-care Behaviors in Patients With Multiple Sclerosis in the Southeast of Iran: Developing a Model for Prac- } \\
\text { tice. Basic and Clinical Neuroscience, 11(5), 687-700. http://dx.doi.org/10.32598/bcn.11.5.1670.1 }\end{array}$ \\
dol http://dx.doi.org/10.32598/bcn.11.5.1670.1
\end{tabular}

Article info:

Received: 07 Jan 2019

First Revision: 25 Jan 2019

Accepted: 15 Sep 2019

Available Online: 01 Sep 2020

Keywords:

Self-care, Health promotion, Multiple Sclerosis, Structural equation model

\section{ABSTRACT}

Introduction: Promoting self-care practice, as a critical strategy for enhancing the quality of life in patients with Multiple Sclerosis (MS) is a challenging issue. This study aimed to propose a model of health-promoting self-care behaviors in MS patients.

Methods: In this cross-sectional study, 200 patients with MS, who had referred to the Hospital for Special Diseases in Kerman City, Iran, were chosen. The main data collection instruments were the multiple sclerosis knowledge questionnaire, the Rosenberg self-esteem scale, multiple sclerosis self-efficacy scale, questionnaire of perceived barriers and benefits of selfcare behaviors, social support, the health promotion lifestyle profile II, and resilience and sense of coherence scale. Data analysis was conducted in SPSS V. 22 and AMOS18 software. The Structural Equation Modeling (SEM) was also used for further analysis of data

Results: The model explained $82 \%$ of variance in Health-Promoting self-care Behavior (HPB). The results of the final model obtained from the SEM showed that self-efficacy $(\beta=0.53, \mathrm{SE}=0.04, \mathrm{P}=0.007)$, self-esteem $(\beta=0.39, \mathrm{SE}=0.04, \mathrm{P}=0.005)$, social support $(\beta=0.36$, $\mathrm{SE}=0.04, \mathrm{P}=0.009)$, sense of coherence $(\beta=0.34, \mathrm{SE}=0.07, \mathrm{P}=0.006)$, resilience $(\beta=0.33$, $\mathrm{SE}=0.07, \mathrm{P}=0.018)$, and perceived benefits $(\beta=0.25, \mathrm{SE}=0.05, \mathrm{P}=0.009)$ had a positive and significant relationship with HPB.

Conclusion: The self-care empowerment model in patients with MS presented in this study can be used as a framework for designing health promotion interventions to improve the quality of life of patients with MS. 


\section{Highlights}

- According to the final model of the path analysis, social support, perceived benefits, self-efficacy, and resilience with direct and indirect paths are significantly correlated with Health-Promoting self-care Behavior (HPB).

- Self-esteem was positively and indirectly correlated with HPB and the sense of coherence was directly correlated with HPB.

- In this regard, self-efficacy followed by self-esteem and social support are the most influential variables on HPB.

\section{Plain Language Summary}

Multiple Sclerosis (MS) affects all aspects of the individual's health, including physical, mental, and social dimensions. In addition to drug therapy, physicians and health staff should pay special attention to self-care in MS patients. The results of some studies on MS patients suggest that self-care programs reduce MS complications, such as depression and stress, boost self-esteem, provide an appropriate health-promoting model, satisfy basic health needs, increase the effectiveness of health education and health promotion programs, and contribute to understanding and defining the key elements of long-term behavior modification. The present study adopts a cross-sectional approach, using the main constructs of Simmons' health-promoting self-care behaviors model as well as important and effective self-care variables to present a model of Health-Promoting self-care Behavior (HPB) in MS patients. Path analysis was utilized to test the primary version of the conceptual model and yield a final model in addition to identifying the direct and indirect effects of each path and standardized effects. The final model revealed that self-esteem, social support, perceived benefits, self-efficacy, resilience, and sense of coherence were the main predictors of HPB. Therefore, this model can be adopted in interventions and self-care training programs for MS patients.

\section{Introduction}

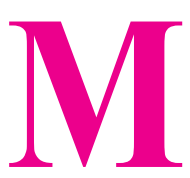

ultiple Sclerosis (MS) is one of the prevalent diseases of the $21^{\text {st }}$ century. It affects all aspects of an individual's health, including physical, mental, and social aspects (Mousavizadeh, Dastoorpoor, Naimi, \& Dohrabpour, 2018). The major physical problems of MS patients that should be managed are pain, weakness and fatigue, visual impairment, muscle spasm, urinary and stool incontinence (While, Ulman, \& Forbes, 2007). Demyelination of nerve fibers not only affects sensory and motor functions, but also brings about psychopathological symptoms (Haussleiter, Brüne, \& Juckel, 2009). Several studies have shown high levels of stress, low self-confidence, depression, and mental distress in these patients. About $50 \%-60 \%$ of patients suffer from depression and $25 \%-40 \%$ from anxiety and stress (Dennison, Moss-Morris, \& Chalder, 2009). These side effects, in general, influences the psychological health of these individuals. Thus, the patients need training on how to overcome these complications (Dennison et al., 2009; While et al., 2007). Physicians, health, and nursing staff should pay special attention to self-care in MS patients besides drug therapy (Amato \& Portaccio, 2012).
Evidence suggests that conscious self-care can help prevent and control many mental and physical consequences of chronic diseases and reduce their economic burden; therefore, special attention should be allocated to counseling and empowering patients (both physical and mental) (Adams et al., 2003).

Self-care is a practice in which a person, independent of others, take care of himself or herself (Naroie, Naji, , Abdeyazdan, \& Dadkani, 2012). The results of some studies on MS patients have shown that self-care programs alleviate MS complications, including depression, anxiety, and stress on the one hand, and boost self-esteem and emotional representation on the other hand (Hazhir F, Ahadi H, Pourshahbaz A, \& Rezaei M, 2012). Other studies have reported factors that can facilitate self-care behaviors in these patients. For example, people who have high self-efficacy and self-esteem believe that they can change their behavior and engage in self-care behaviors to promote their health and quality of life (Amtmann et al., 2012). One of the factors that improves self-care behaviors in patients with chronic disease is social support. Studies have shown that the sense of loneliness and perceived social support are related to the level of self-efficacy in patients. MS patients grow disconnected from society and lose social support, thus becoming more vulnerable to social disadvantages, economic crises, 
and physical and mental health problems (Fry \& Debats, 2012; Ghasemipour \& Nazai, 2012). Besides, the results of previous studies have shown a significant relationship between patients) improved awareness of self-care behaviors and positive changes in the disease, including diminished anxiety, and improved quality of life. Studies have also demonstrated the key role of the two components of resilience and sense of coherence in choosing a healthy lifestyle and adopting health-promoting self-care behaviors in patients with chronic MS (Luthar, Cicchetti, \& Becker, 2000; Scherer \& Bruce, 2001; WainWright et al., 2008).

Considering the above discussion about the factors influencing health-promoting self-care behaviors (self-efficacy, self-esteem, social support, perceived barriers and benefits, awareness, resilience, and sense of coherence), providing an appropriate health-promoting model and satisfying basic health needs will increase the effectiveness of health education and health promotion programs. These outcomes in turn contribute to understanding and defining the key elements for behavior modifications in the long-term (Estebsari et al., 2018).

A variety of theoretical models have been introduced for health-promoting behaviors by experts. In this context, a relatively comprehensive model called "the health-promoting self-care behaviors model" was proposed by Simmons. The model for health-promoting self-care behavior is one of the patterns that is commonly used in the field of behavior changes. This model presents a comprehensive conceptual model called the health-promoting self-care behavior model, which is based on the Orem self-care model (1985), the model of client health behavior (1982), and the Pender's health promotion model (1987). This background provides a broad and extensive framework for identifying and explaining hypothetical factors affecting decision-making, performance, design, and assessment of interventions (Simmons S, 1990a). Given the wide array of components included in Simmons' health-promoting self-care behaviors model, the model is primarily conceptual and hypothetical and draws on other theories and models. In this regard, it is fairly eclectic, making it a useful general guide for designing educational interventions. However, given the demographic variations and the types of chronic diseases, each subject must be matched concerning the constructs of Simmons' model. Also, as discussed in the introduction section, the role of other important factors such as social support, resilience, and the sense of coherence in health-promoting self-care behaviors in MS patients has been documented. Therefore, the present study, based on the main constructs of Simmons' healthpromoting self-care behaviors model as well as impor- tant and effective self-care variables, adopts a cross-sectional approach to present a model of health-promoting self-care behavior in MS patients.

\section{Materials and Methods}

\subsection{Study type and research method}

This cross-sectional study was undertaken in 2018 on 200 MS patients who had referred to Kerman Hospital for Special Diseases using a simple random sampling method. Kerman City, as the capital of Kerman Province, is the largest province of Iran. With a development rate of 0.251 , this province has been rated as one of the deprived areas of Iran (rank 10) in terms of health indicators (Yazdani \& Montazer, 2018). According to the latest Census in 2016, Kerman has a population of about 24738 (Tabatabaei et al., 2017).

\subsection{The inclusion and exclusion criteria}

The inclusion criteria consisted of medical diagnosis of the relapsing-remitting type of MS, disability scale (EDSS) below 5 (i.e. patients that are not at the stage of disability), an age range of 19 to 35 years, signing informed consent for participation in the study, ability to understand the content (minimum primary education) and complete the questionnaire.

The exclusion criteria included abandoning the study for any reason or contracting a disease that prevented the participation of the subjects in the study.

\subsection{Sample size}

Based on the sample size formula in the correlation studies (Hulley, Cummings, Browner, Grady, \& Newman, 2013), a sample of 173 was estimated with a confidence interval of $95 \%$ and the test power of $80 \%$. Considering a $10 \%$ probable loss, a final sample size of 200 was chosen. The patients were selected using a simple random sampling method.

\subsection{Data collection instruments}

The study data were collected using 10 self-report questionnaires, as described below.

1-Demographic Checklist: It contains demographic information such as age, sex, marital status, educational level, number of children, living area (city, village), employment status, and monthly income. 
2- Multiple Sclerosis Knowledge Questionnaire (MSKQ): It was designed by Giordano et al. in 2009. This questionnaire, which measures MS patients' knowledge about their illness, consists of 25 three-choice items (True, False, Neutral). The total score of the scale ranges between 0 and 25 (Giordano et al., 2010). After reviewing and introducing some modifications, a 26-item questionnaire was developed, which was suitable for the diagnostic status of patients with MS in Iran, and was validated. The total score of the scale ranged between 0 and 26 and it had a Cronbach alpha coefficient of 0.76 (Safarpour, 2014).

3- Rosenberg Self-Esteem Scale (RSE): This scale, designed by Rosenberg in 1965, contains 10 two-choice items (I agree, I disagree). The total score of the scale ranges between 0 and 10 (Rosenberg, 1965). It was validated for MS patients in Iran; this scale had a Cronbach alpha coefficient of 0.97 (Aghayi, Gozal, Zeinali, Ahmadi, 2017).

4- Multiple Sclerosis Self-efficacy Scale (MSSS): Designed by Rigby et al. in 2003, this scale includes 11 items that are rated on a 5-point Likert-type scale (strongly agree, agree, neutral, disagree, strongly disagree). The total score of the scale ranges between 11 and 55 points. The scale comprises three subscales of "independence and activity", "personal control", and "concerns and interests" (Rigby, Domenech, Thornton, Tedman, \& Young, 2003). This scale was validated for MS patients in Iran and its Cronbach alpha coefficient was reported as 0.90 (Tanhaye Reshvanlo \& Soleimanian, 2012).

5. The scale of perceived barriers in MS: This scale was designed by Morowati-Sharifabad et al. in 2016 to determine the perceived barriers to self-care activities in MS patients. It contains 12 items that are rated on a 3-point Likert-type scale (never, a little, a lot). The total score of the scale ranges between 0 and 24 with higher scores indicating higher perceived barriers to self-care health-promoting behaviors in patients with MS. The face and content validities of the questionnaire was confirmed by health education practitioners and specialists and its Cronbach alpha coefficient was reported as 0.86 (Morowatisharifabad, Momeni, Eslami, DehghaniTafti, \& Hakimzadeh, 2016).

6. The scale of perceived benefits in MS: This scale was also designed by Morowati Sharifabad et al. in Iran in 2016 to determine the perceived benefits of self-care activities in MS patients. It contained 6 items assessed on a 5-point Likert-type scale (totally agree, agree, neutral, disagree, totally disagree). The total score of the scale ranges between 6 and 30 points. The face and content validities of the scale were confirmed by health education specialists and its Cronbach alpha coefficient was reported as 0.79 (Morowati Sharifabad et al., 2016).

7- Connor-Davidson, Resilience scale (CD-RISC): Designed by Connor and Davidson in 2003, this scale includes 25 items that are assessed on a 5-point Likert scale (totally wrong, somewhat wrong, neutral, somewhat correct, totally correct). The total score ranges between 0 and 100 (Connor, \& Davidson, 2003). This scale has been validated in Iran and its Cronbach alpha coefficient was reported as 0.84 (Hagh Ranjbar, Kakavand Borjali, \& Bermas, 2011).

8- Sense of Coherence (SOC) Scale: Developed by Flensborg-Madsen et al. in 2006, this scale contains 35 questions in the form of multiple-choice questions (yes, no, I do not know). The total score of the scale ranges between 35 and 105 (Flensborg-Madsen, Ventegodt, \& Merrick, 2006). This scale has been validated in Iran and its Cronbach alpha coefficient was reported as 0.89 (Ehteshamzadeh, Sabrinazarzadeh, \& Mamarbashi, 2013).

9- Medical Outcomes Study-Social Support Survey (MOS-SSS): The survey was designed by Stewart et al. in 1991 to study medical consequences. It includes 19 questions rated on a 5-point Likert-type scale (never, often, sometimes, most often, always). The total score of the scale ranges between 19 and 95 points. It measures 5 aspects of social support: concrete support, emotional support, information, kindness, and positive social interaction (Stewart, Hays, \& Ware, 1988). The scale has been validated in Iran and its Cronbach alpha coefficient was reported as 0.97 (Mohammadzadeh, Sayehmiri, \& Mahmoudi, 2016).

10-Health-Promoting Lifestyle Profile II (HPLP II): It was developed by Walker et al. in 1995. This questionnaire includes 52 items that are assessed on a 4-point Likert scale (never, sometimes, often, and always) and measures 6 dimensions of physical activity, nutrition, spiritual growth, interpersonal relation, stress management, and health responsibility. The overall score of the scale ranges from 52 to 208 (Walker, Sechrist, \& Pender, 1995). This tool has been validated in MS patients in Iran and its Cronbach alpha coefficient was reported as 0.82 (Dashti-Dehkordi, Yousefi, Maghsoudi, Etemadifar, \& Maghsoudi, 2017)

In this study, the questionnaires validated in Iran, as described above, were used for data collection. Given that 


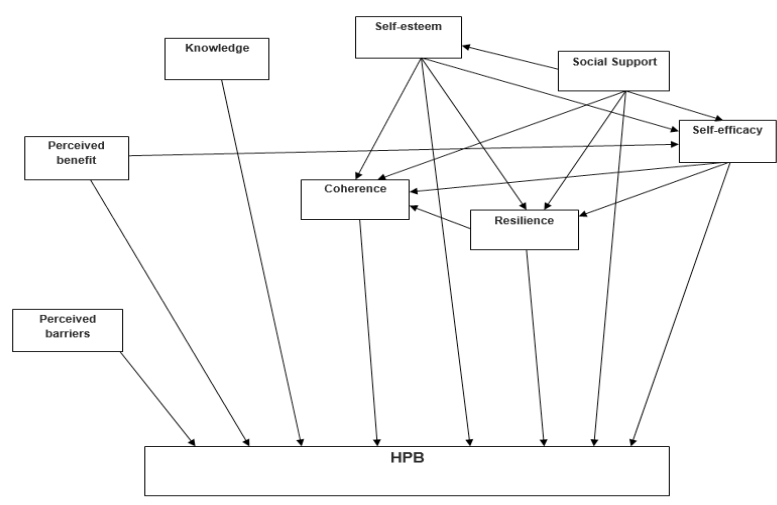

NEUR SCIENCE

Figure 1. Conceptual framework of health-promoting self-care behavior in MS patients (Ma et al., 2013; O’Brien, 1993; Simmons, 1990b; Wainwright et al., 2007)

multiple questionnaires had to be filled out by patients, to prevent fatigue and reduced accuracy in the target group, the scales were completed in two consecutive days.

\subsection{Ethical considerations}

After obtaining the necessary permits for conducting the research and making arrangements with the relevant authorities, written informed consent regarding the voluntary nature of participation in the study was obtained from MS patients. They were also ensured about the confidentiality of information, guaranteed that if the research was terminated, they would not suffer any physical or moral harm. Ethical approval was obtained from the Ethics Committee of Shiraz University of Medical Sciences (IR.SUMS.REC.1396.182) (Project No: 15554).

\subsection{Study analysis}

Before the analysis, the normality of the main research variables was assessed with the Shapiro-Wilk test. Data analysis was conducted in SPSS V. 22 (SPSS; Inc, Chicago, IL, USA) and AMOS18 ( AMOS: ADC, Chicago, IL, USA). Descriptive statistics, the Pearson correlation coefficient, and path analysis were used to test the primary version of the conceptual model, provide a final model and identify the direct and indirect effects of each path and standardized effects. During data analysis, various model indicators such as Comparative Fit Index (CFI), the Goodness of Fit Index (GFI) (above 0.9), Root Mean Square Error of Approximation (RMSEA) (below $0.08)$, and the Chi-square index/degrees of freedom $\left(\chi^{2}\right)$ df) (below 3) were evaluated, all of which indicate the suitability of the model. The primary conceptual model

Table 1. Descriptive statistics of theoretical constructs as potentials determinants of health-promoting self-care behaviors in the participants $(\mathrm{n}=200)$

\begin{tabular}{|c|c|c|c|c|}
\hline Variables & $\mathbf{N}$ & Mean $\pm S D$ & Min. & Max. \\
\hline Perceived barriers & 200 & $13.13 \pm 4.8$ & 0.0 & 20.0 \\
\hline Perceived benefit & 200 & $21.4 \pm 4.5$ & 11.0 & 30.0 \\
\hline Knowledge & 200 & $14.1 \pm 4.4$ & 0.0 & 24.0 \\
\hline Self-esteem & 200 & $6.2 \pm 2.4$ & 0.0 & 10.0 \\
\hline Social Support & 200 & $59.6 \pm 17.6$ & 19.0 & 95.0 \\
\hline Self-efficacy & 200 & $31.8 \pm 7.3$ & 18.0 & 51.0 \\
\hline Coherence & 200 & $73.2 \pm 13.3$ & 40.0 & 103.0 \\
\hline Resilience & 200 & $53.7 \pm 18.7$ & 17.0 & 100.0 \\
\hline Health promoting self-care behaviors & 200 & $117.2 \pm 34.6$ & 52.0 & 208.0 \\
\hline
\end{tabular}




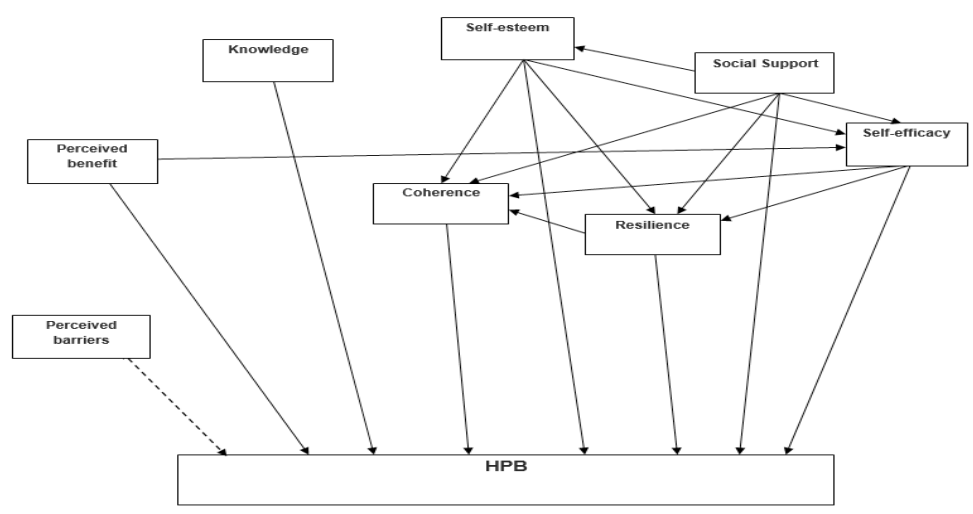

NEUR SCIENCE

Figure 2. The primary model of health-promoting self-care behavior based on the Pearson correlation results (Source: original data)

---- Significant relationship; --- Insignificant relationship

for improving health-promoting self-care behaviors in MS patients, based on the main constructs of the Simmons' health-promoting self-care behaviors model and review of the literature, is presented in Figure 1. The level of significance was less than 0.05 in all analyses.

\section{Results}

The Mean \pm SD age of the participants was $29.9 \pm 8.3$ years. Concerning gender, $67 \%$ of the subjects were female and the rest were male. In terms of education, $62.5 \%$ had a diploma and tertiary degrees, and the rest held high school or lower education. More than half of the participants were married (60\%). As for employment, $45 \%$ were employed and the rest were unemployed.
In this study, of 220 questionnaires distributed, 200 were completed and returned (response rate $=90.90 \%$ ). Of 20 subjects who failed to complete the questionnaire and withdrew from the study, 11 noted dissatisfactions and 9 physical problems as the main reason.

Table 1 presents the descriptive statistics of the constructs of the health-promoting self-care behaviors model. The mean values of the constructs of the healthpromoting self-care behavior model were as follows: perceived barriers (13.13), perceived benefits (21.4), knowledge (14.1), self-esteem (6.2), social support (59.6), self-efficacy (31.8), sense of coherence (73.2), resilience (53.7), and Health-Promoting self-care Behavior (HPB) (117.2).

Table 2. The correlation matrix of the health-promoting self-care behavior model $(n=200)$

\begin{tabular}{|c|c|c|c|c|c|c|c|c|c|}
\hline Variables & $\begin{array}{c}\text { Perceived } \\
\text { Barrier }\end{array}$ & $\begin{array}{c}\text { Perceived } \\
\text { Benefit }\end{array}$ & Knowledge & $\begin{array}{c}\text { Self- } \\
\text { esteem }\end{array}$ & $\begin{array}{c}\text { Social } \\
\text { Support }\end{array}$ & $\begin{array}{c}\text { Self- } \\
\text { efficacy }\end{array}$ & $\begin{array}{c}\text { Coher- } \\
\text { ence }\end{array}$ & $\begin{array}{l}\text { Resil- } \\
\text { ience }\end{array}$ & $\begin{array}{c}\text { Health-promot- } \\
\text { ing Self-care } \\
\text { Behavior }\end{array}$ \\
\hline Perceived barriers & 1 & & & & & & & & \\
\hline Perceived benefit & -0.018 & 1 & & & & & & & \\
\hline Knowledge & 0.039 & $0.504^{* *}$ & 1 & & & & & & \\
\hline Self-esteem & $-0.153^{*}$ & $0.575^{* *}$ & $0.503^{* *}$ & 1 & & & & & \\
\hline Social Support & $-0.145^{*}$ & $0.482^{* *}$ & $0.347^{* *}$ & $0.492 * *$ & 1 & & & & \\
\hline Self-efficacy & -0.123 & $0.663^{* *}$ & $0.570 * *$ & $0.754^{* *}$ & $0.629 * *$ & 1 & & & \\
\hline Coherence & -0.134 & $0.625^{* *}$ & $0.448 * *$ & $0.735^{* *}$ & $0.704^{* *}$ & $0.811^{* *}$ & 1 & & \\
\hline Resilience & -0.099 & $0.630^{* *}$ & $0.464^{* *}$ & $0.751^{* *}$ & $0.624^{* *}$ & $0.868^{* *}$ & $0.816^{* *}$ & 1 & \\
\hline $\begin{array}{l}\text { Health promoting } \\
\text { self-care behavior }\end{array}$ & -0.078 & $0.671^{* *}$ & $0.483^{* *}$ & $0.716^{* *}$ & $0.675^{* *}$ & $0.846^{* *}$ & $0.854^{* *}$ & $0.842 * *$ & 1 \\
\hline
\end{tabular}

${ }^{*} \mathrm{P}<0.001 ; * * \mathrm{P}<0.05$ 


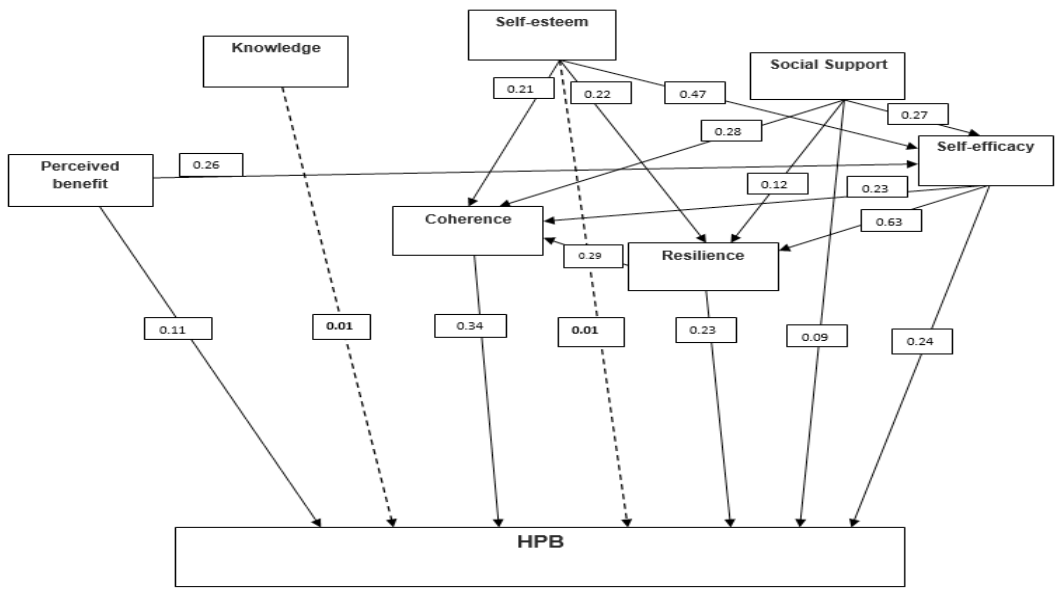

NEUR SCIENCE

Figure 3. The modified model of pathway analysis for health-promoting self-care behaviors (Source: Original data)

-_-- Significant relationship; - - - Insignificant relationship

As the results of the descriptive analysis suggest, the mean scores of the predictor constructs of self-care behaviors in MS patients were higher than $50 \%$ of the maximum construct scores. Also, the mean score of the patients' HPB was 117.2 , which is more than $50 \%$ of the maximum score (104), indicating that the participants of our study were in desirable conditions in this respect.

According to the correlation matrix, the correlation coefficient was between 0.018 and 0.868 . The sense of coherence $(r=0.854)$ and perceived barriers $(r=-0.078)$ exhibited the strongest and weakest correlations with the HPB variable. Based on the results of the Pearson correlation coefficient, perceived benefits, knowledge, selfesteem, social support, self-efficacy, sense of coherence, and resilience, except for perceived barriers, had a direct and significant relationship with the HPB response variable at the significant level of $\mathrm{P}<0.001$ (Table 2). Therefore, perceived barriers were removed from the primary hypothetical model (Figure 2) and the model fitness was assessed using the path analysis.

In the analysis of the modified model, the results of path analysis suggested that the perceived benefits, sense of coherence, resilience, social support, and self-efficacy had a direct and significant relationship with the HPB variable. However, the variables of knowledge and selfesteem were not directly correlated with the HPB variable (Figure 3). Therefore, the modified model of the path analysis was re-fitted after removing the insignificant variables.

The final model of the path analysis is shown in Figure 4. We tested the goodness of fit of the final model. The
CFI, GFI, RMSEA, and $\chi^{2} / \mathrm{df}$ were estimated at 1.00 , $0.99,0.04$, and 1.28 , respectively; the results exhibit the desirable fitness of the model.

In the final study of the path analysis, the results show that social support, perceived benefits, and self-efficacy and resilience directly or indirectly were positively correlated with HPB (Table 3). The standardized beta $(\beta)$ coefficients from the direct path indicate that for each unit increase in social support, perceived benefits, selfefficacy, and resilience, the mean HPB score increases to $0.09,0.11,0.24$, and 0.23 , respectively, and vice versa (Figure 4).

The self-esteem variable illustrated a positive and significant correlation with HPB only indirectly $(\beta=0.39$, $\mathrm{SE}=0.04, \mathrm{P}=0.005$ ). The sense of coherence variable also showed a positive and significant correlation with HPB only with a direct path $(\beta=0.34, \mathrm{SE}=0.07, \mathrm{P}=0.006)$. In this regard, considering their total effect on HPB, selfefficacy, followed by self-esteem and social support (Table 3 ) are the most influential variables, respectively. Table 3 presents further details of the final model.

Finally, the above model suggests that $82 \%$ of variations in the HPB variable $\left(\mathrm{R}^{2}=0.82\right)$ can be explained by six constructs of self-esteem, social support, perceived benefits, self-efficacy, resilience, and sense of coherence. The remaining $18 \%$ is defined by other variables.

\section{Discussion}

The health-promoting self-care behaviors are the major factors affecting the ability of MS patients, stimulating 


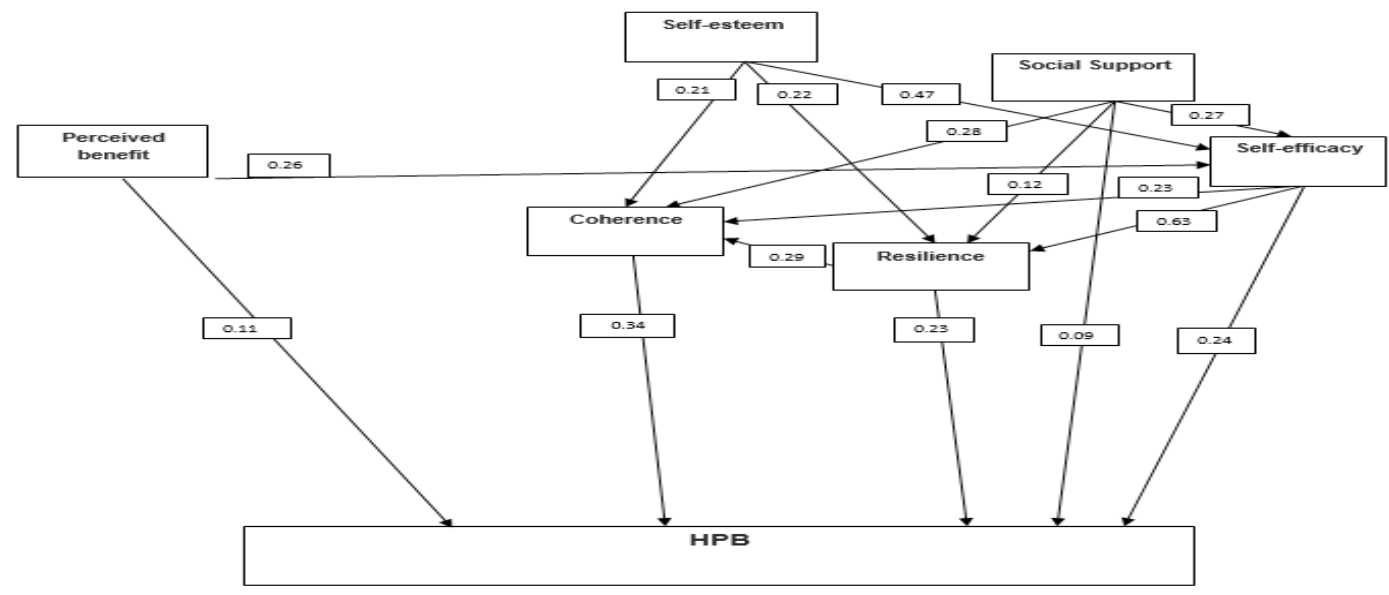

Figure 4. The final model of pathway analysis of health-promoting self-care behavior

NEUR SCIENCE

Numbers indicate the standardized path coefficient of the model (Source: original data); Significant relationship

repressed, and forgotten capabilities that empower them to overcome their disabilities (Masoudi, Mohammadi, Nabavi, \& Ahmadi, 2008). The present study revealed an overall good fit between the proposed model and the data. According to the results, self-efficacy, self-esteem, social support, sense of cohesion, resilience, and perceived benefits are the main predictors of health-promoting self-care behaviors among which self-efficacy exerted the highest effect.

Based on the results of this study, $67 \%$ of MS patients were female. This finding is consistent with those reported in previous studies according to which the female patients outnumber the male patients by 3 to 4 times (Mousavizadeh et al., 2018; Sedaghat, Jessri, Behrooz, Mirghotbi, \& Rashidkhani, 2016). The higher rate of MS among women may be related to their physiological features such as sex hormones and stress. Additionally, the growing incidence of MS in females suggests that hormonal differences make women more susceptible to environmental risk factors (Izadi, Nikseresht, Poursadeghfard, Borhanihaghighi, \& Heydari, 2015).

Like similar studies, the mean age of participants in this research was 29.9 years (Mousavizadeh et al., 2018). This may be due to a variety of adolescence-related factors, such as education, university entrance exam, occupation, or marriage, which are major determinants of one's future life and failure in any of these areas could be a source of stress.

The number of married participants in this study was twice that of single adults. This finding may be prompted by factors related to marriage and childbearing, which guide individuals into important stages of life, and failure to adapt to new situations may be a source of stress and anxiety, which are major predictors of MS. Also, more than $50 \%$ of patients were university students or had a university degree, which is in agreement with the findings of Abedini et al. (2016). The results of studies have exhibited that the effect of education on health is greater than that of income and occupation, as illiteracy can be linked to a sense of irresponsibility concerning health and treatment. Moreover, people who have a university degree are more likely to appreciate the effect of health-promoting self-care behaviors (Karimy, Abedi, Amin-Shokravi, \& Tavafian, 2013).

Furthermore, the current study suggests a positive and significant correlation between self-efficacy and HPB. The results of the path analysis model exhibited that, both in the direct and the indirect paths, with one unit increase in self-efficacy, the mean HPB score rose by 0.24 and 0.28 , respectively. Also, according to the results, the self-efficacy variable exerts the highest effect on HPB, which is in agreement with the results of previous studies (Finn, 2006; Polsingchan , 2010; Salahshoori et al., 2015). In a 2007 study by Wu et al. on patients with type 2 diabetes, health-promoting self-care behaviors were found to be in a positive and significant relationship with the duration of the disease, the outcome expectation, and self-efficacy of patients. The researchers concluded that self-efficacy improvement models contribute to the adoption of health-promoting self-care behaviors (Wu et al., 2007). In his model of self-promotion, Pender found that self-efficacy was one of the major predictors 
Table 3. Directions and standard coefficients of the pathway model

\begin{tabular}{|c|c|c|c|c|c|c|c|c|c|}
\hline \multirow{2}{*}{ Pathway } & \multicolumn{3}{|c|}{ Total Effect } & \multicolumn{3}{|c|}{ Indirect Effect } & \multicolumn{3}{|c|}{ Direct Effect } \\
\hline & $\beta^{*}$ & SE & $\mathbf{P}$ & $\beta^{*}$ & SE & $\mathbf{P}$ & $\beta^{*}$ & SE & $\mathbf{P}$ \\
\hline Self-esteem $>$ HPB & 0.39 & 0.04 & $0.005^{¥}$ & 0.39 & 0.04 & $0.005^{¥}$ & --- & --- & --- \\
\hline Social Support> HPB & 0.36 & 0.04 & $0.009^{*}$ & 0.28 & 0.04 & $0.009^{¥}$ & 0.09 & 0.04 & $0.047^{*}$ \\
\hline Perceived benefit> HPB & 0.25 & 0.05 & $0.009^{¥}$ & 0.14 & 0.03 & $0.007^{¥}$ & 0.11 & 0.04 & $0.008^{*}$ \\
\hline Self-efficacy> HPB & 0.53 & 0.04 & $0.007^{¥}$ & 0.28 & 0.05 & $0.032^{¥}$ & 0.24 & 0.06 & $0.007^{*}$ \\
\hline Resilience> HPB & 0.33 & 0.07 & $0.018^{*}$ & 0.10 & 0.03 & $0.004^{¥}$ & 0.23 & 0.07 & $0.020^{*}$ \\
\hline Coherence > HPB & 0.34 & 0.07 & $0.006^{¥}$ & -. & -. & -. & 0.34 & 0.07 & $0.006 *$ \\
\hline
\end{tabular}

$\chi^{2} / \mathrm{df}=1.28, \mathrm{GFI}=0.99, \mathrm{CFI}=1.00, \mathrm{IFI}=1.00, \mathrm{RFI}=0.98, \mathrm{NFI}=1.00, \mathrm{RMSEA}=0.037$, Hoelter Index=590

NEUR SCIENCE

HPB: Health-promoting self-care behavior; $x^{2} /$ df: Chi-squared/degree of freedom; GFI: The goodness of fit index; CFI: Comparative fit index; IFI: Incremental fit index; RFI: Relative fit index; NFI: Normed fit index; RMSEA: Root mean square error of approximation; * Standardized beta; ${ }^{*}$ P values are significant.

of health. Moreover, $86 \%$ of studies on the health promotion model has endorsed the role of self-efficacy as a predictor of behavior (Pender, Murdaugh, \& Parsons, 2006). However, Wendling et al. found no significant relationship between patients' self-efficacy and their selfcare behaviors (Wendling \& Beadle, 2015). This may be due to the diversity of research environments and subjects, or data gathering tools.

The current findings indicate a positive and significant correlation between self-esteem and HPB. According to the results of path analysis, in an indirect path, with improved self-esteem, the mean HPB score rises by 0.39 , which is consistent with the literature. For example, the study of Madani et al. on 38 patients with MS revealed a significant relationship between the self-esteem of patients and health-promoting self-care behaviors. Patients with a higher sense of self-esteem were more likely to adopt health-promoting self-care behaviors to deal with their problems, while patients with low self-esteem tended to adopt emotionally-focused oppositional methods (Madani, Navipour, \& Rouzbayani, 2008). Also, in a study on the relationship between self-esteem, social support, and oppositional behavior in MS patients, O'Brien found a significant relationship between selfesteem and problem-oriented oppositional methods, including health-promoting behaviors. Moreover, the necessity of assessing self-esteem, social support, and coping behavior in patients with MS has been emphasized (O'Brien, 1993). Health-promoting self-care behaviors are one of the coping behaviors in MS patients that encourages patients to take responsibility for their health (Acton \& Malathum, 2000). This correlation, however, was not observed in the study of Sinclair et al. and Von Bothmer et al. (Sinclair \& Scroggie, 2005; Von Bothmer \& Fridlund, 2005). This discrepancy of results could be attributed to different research environments, subjects, or data gathering tools.

Based on these findings, there was a positive and significant correlation between social support and HPB. Hence, the results of the path analysis model revealed that both in the direct and the indirect paths, one unit increase in the social support variable raised the mean HPB score by 0.92 and 0.28 , respectively. In practice, a high level of social support can improve health-promoting self-care behaviors. In this context, other studies have demonstrated the positive impact of social support on HPB (Alizadeh, Keshavarz, Mirghafourvand, \& Zayeri, 2018; Ballard, 2009). However, the study of Yi Ps et al. has not reported a relationship between perceived social support and HPB (Pan, Cameron, Desmeules, Morrison, Craig, Jiang, 2009). This discrepancy of results could be attributed to different research environments or data gathering tools. Social support is critical to health promotion as it accelerates physical and emotional needs, protecting individuals against stressful living conditions (Ballard, 2009). It is, therefore, important to boost social support (financial, emotional, and informational) in MS patients to promote HPB and reduce the wide range of problems associated with the disease, including financial problems linked to the purchase of drugs and emotional problems (Mazaheri, Fanian, \& Zargham-Boroujeni, 2011). 
The results also exhibit a positive correlation between the sense of coherence and HPB. In the direct path, a unit increase in the sense of coherence augmented the average HPB score by 34.4. Other researchers reported similar results. For example, in a pilot study on students in Finland, physical activity was found to be positively related to the sense of coherence (Hassmen, Koivula, \& Uutela, 2000). Another study also suggested that a low sense of coherence was strongly linked to smoking behaviors (Glanz, Maskarinec, \& Carlin, 2005).

In the present study, a positive and significant correlation was observed between resilience and HPB. The results of the path analysis model revealed that both in the direct and the indirect paths, one unit increase in the resilience raised the mean HPB score by 0.23 and 0.10 , respectively. In this regard, the 2013 study of Chang on patients with chronic renal disease reported a positive and significant relationship between resilience and HPB dimensions (Ma et al., 2013).

Since two constructs of resilience and sense of coherence are predictable, problem-oriented decision-making interventions can be employed to help individuals learn how to come to terms and cope with their diseases. Particularly, stress management training for MS patients can affect both the sense of coherence and the degree of patients' resilience. In other words, in chronic diseases, it is essential to help patients set a target for recovery, hamper the progression of the disease, strengthen positive thinking and the adoption of a positive attitude towards life and future, and mitigate disappointment (as studies have shown that disappointment in chronic patients exerts influence on resilience). In the same vein, the ability to communicate with others and establish useful social networks are fundamental as expanded communication network precludes isolation and reduces depression and frustration in patients (Dayapoğlu, \& Tan, 2012; Valizadeh, Sohrabnejad, Mehraban, \& Ahmadbokani, 2014).

According to the results, perceived benefits are also positively and significantly correlated with HPB. Moreover, the results of the final path analysis model indicated that the standardized coefficients of direct and indirect paths of perceived benefits of HPB were 0.19 and 0.14 , respectively. In other words, with increased perceived benefits, the mean HPB score soared by 0.19 and 0.14 , which is statistically significant. In this regard, several studies have reported the significant correlation between perceived benefits and health-promoting self-care behavior in chronic diseases (Aalto \& Uutela, 1997; Koch, 2002), though this correlation was not observed in the study of Gillibrand \& Stevenson, (2006). This discrep- ancy of results could be attributed to different research environments and or data gathering tools.

\subsection{Study strengths and limitations}

This is the first study to adopt SEM to test a comprehensive theoretical model that combines the constructs of Simons' health-promoting self-care behavior model and other constructs derived from the literature review as predictors of self-promoting self-care behaviors in MS patients in Iran. The new model presented in the study, i.e. "self-care empowerment model in MS patients", demonstrates strong predictors of health-promoting selfcare behaviors (both direct and indirect) in MS patients. It is one of the major strengths of this study besides its innovation.

Our study also had several limitations. One major limitation of the study was the reluctance of some patients to participate in the project. Another limitation was concerned with data gathering based on patients' self-report, which precluded accurate observations by the researcher. Therefore, an objective review and periodic follow-ups might yield different outcomes. The last limitation had something to do with the nature of MS disease and the large number of questions, which made the completion of questionnaires an exhausting task for some patients.

It is suggested that future interventional studies on promoting self-care behaviors in patients with MS based on the above model as well as qualitative studies identify other predictors of health-promoting self-care behavior. Moreover, since it was not possible to evaluate health status in the research environment and patients' residence, it is recommended that future research considers this issue to account for marginalized patients.

\section{Conclusion}

The study findings revealed that a higher level of selfefficacy, self-esteem, social support, sense of coherence, resilience, and perceived benefits improved health-promoting self-care behaviors in MS patients. The current study also suggested that besides the main constructs of the Simmons model, factors such as resilience, sense of coherence, and social support play significant roles in the adoption of health-promoting self-care behaviors. Therefore, these factors should be considered by health professionals and physicians in designing and implementing programs for MS patients. In conclusion, this model of health promotion is recommended as a way of improving self-care behaviors in MS patients. 


\section{Ethical Considerations}

Compliance with ethical guidelines

The study was approved by the Ethics Committee of Shiraz University of Medical Sciences (Ref: IR.SUMS. REC.1396.182) and written consent forms were taken from all participants.

\section{Funding}

The research project was financially supported by Shiraz University of Medical Sciences, Shiraz, Iran (Grant No: 15554).

\section{Authors' contributions}

All authors were equally contributed in preparing this article.

\section{Conflict of interest}

The authors declared no conflict of interest.

\section{References}

Aalto, A. M., \& Uutela, A. (1997). Glycemic control, self-care behaviors, and psychosocial factors among insulin treated diabetics: A test of an extended health belief model. International Journal of Behavioral Medicine, 4(3), 191. [DOI:10.1207/ s15327558ijbm0403_1] [PMID]

Abedini, M., Paksersht, M., Rafiei, A., Valadan, R., Amjadi, O., \& Khajavi, R., et al. (2016). Demographic and clinical characteristics of multiple sclerosis. Journal of Mazandaran University of Medical Sciences, 25(132), 13-22. http://jmums.mazums.ac.ir/ article-1-6725-en.pdf

Acton, G. J., \& Malathum, P. (2000). Basic need status and healthpromoting self-care behavior in adults. Western Journal of Nursing Research, 22(7), 796-811. [DOI:10.1177/01939450022044764] [PMID]

Adams, A. S., Mah, C., Soumerai, S. B., Zhang, F., Barton, M B., \& Ross-Degnan, D. (2003). Barriers to self-monitoring of blood glucose among adults with diabetes in an HMO: A cross sectional study. BMC Health Services Research, 3(1), 1-8. [DOI:10.1186/1472-6963-3-6] [PMID] [PMCID]

Aghayi, M., Gozal, S., Zeinali, M., Ahmadi, N., \& Mirzaei, S. (2017). [The efficiency of problem-solving skills on quality of life and self-esteem of patients with multiple sclerosis (Persian)]. Journal of Psychology New Ideas, 1(1), 29-38. http://jnip. ir/article-1-49-fa.html

Alizadeh, T., Keshavarz, Z., Mirghafourvand, M., \& Zayeri, F. (2018). Investigation of health promoting lifestyle and social support and their correlation among Iranian women with multiple sclerosis. International Journal of Women's
Health and Reproduction Sciences, 6(2), 167-73. [DOI:10.15296/ ijwhr.2018.28]

Amato, M. P., \& Portaccio, E. (2012). Management options in multiple sclerosis-associated fatigue. Expert Opinion on Pharmacotherapy, 13(2), 207-216. [DOI:10.1517/14656566.2012.6477 67] [PMID]

Amtmann, D., Bamer, A. M., Cook, K. F., Askew, R. L., Noonan, V. K., \& Brockway, J. A. (2012). University of Washington self efficacy scale: A new self-efficacy scale for people with disabilities. Archives of Physical Medicine and Rehabilitation, 93(10), 1757-65. [DOI:10.1016/j.apmr.2012.05.001] [PMID]

Ballard FA. (2009). Homeless sheltered women's health promotion behaviors., The University of North Carolina at Greensboro. https://libres.uncg.edu/ir/uncg/f/Ballard uncg_0154D_10116.pdf

Connor, K. M., \& Davidson, J. R. (2003). Development of a new resilience scale: The Connor-Davidson resilience scale (CDRISC). Depression and Anxiety, 18(2), 76-82. [DOI:10.1002/ da.10113] [PMID]

Dashti-Dehkordi, A., Yousefi, H., Etemadifar, M., \& Maghsoudi, J. (2017). Health promotion behaviors and its correlation with some of the demographic factors in patients with multiple sclerosis. Advances in Nursing \& Midwifery, 26(93), 11-18. https://onlinelibrary.wiley.com/doi/abs/10.1002/da.10113

Dayapoğlu, N., \& Tan, M. (2012). Evaluation of the effect of progressive relaxation exercises on fatigue and sleep quality in patients with multiple sclerosis. The Journal of Alternative and Complementary Medicine, 18(10), 983-987. [DOI:10.1089/ acm.2011.0390] [PMID] [PMCID]

Dennison, L., Moss-Morris, R., \& Chalder, T. (2009). A review of psychological correlates of adjustment in patients with multiple sclerosis. Clinical Psychology Review, 29(2), 141-153. [DOI:10.1016/j.cpr.2008.12.001] [PMID]

Ehteshamzadeh P, Sabrinazarzadeh R, \& Mamarbashi M (2013). The relationship between sense of coherence and job performance with intermediation strategis of coping with stress and mental health. Psychological Methods and Models Journal, 3(13), 85-97. https://www.sid.ir/en/journal/ViewPaper.aspx?id $=411402$

Estebsari, F., Dastoorpoor, M., Mostafaei, D., Khanjani, N., Khalifehkandi, Z. R., \& Foroushani, A. R., et al. (2018). Design and implementation of an empowerment model to prevent elder abuse: A randomized controlled trial. Clinical Interventions in Aging, 13, 669. [DOI:10.2147/CIA.S158097] [PMID] [PMCID]

Finn, A. (2006). The relationship between self-efficacy and health promoting behaviors, illness severity, mental health and perceived quality of life in multiple sclerosis patients Modern Psychological Studies, 11(2), 11-24. https://scholar.utc $\mathrm{edu} / \mathrm{mps} / \mathrm{vol11} /$ iss2/3/

Flensborg-Madsen, T., Ventegodt, S., \& Merrick, J. (2006). Sense of coherence and physical health. Testing antonovsky's theory. The Scientific World Journal, 6, 640524. [DOI:10.1100/ tswhhm.2006.232]

Fry, P. S., \& Debats, D. L. (2002). Self-efficacy beliefs as predictors of loneliness and psychological distress in older adults. The International Journal of Aging and Human Development, 55(3), 233-269. [DOI:10.2190/KBVP-L2TE-2ERY-BH26] [PMID] 
Ghasemipour, M., Nazai, H. (2012). [The relationship between quality of life and social support in Multiple Sclerosis patients (Persian)]. Nursing Developement in Health, 3(4-5). http://ndhj. lums.ac.ir/article-1-91-fa.html

Gillibrand, R., \& Stevenson, J. (2006). The extended health belief model applied to the experience of diabetes in young people. British Journal of Health Psychology, 11(1), 155-69. [DOI:10.1348/135910705X39485] [PMID]

Giordano, A., Messmer Uccelli, M., Pucci, E., Martinelli, V., Borreani, C., \& Lugaresi, A., et al. (2010). The Multiple Sclerosis Knowledge Questionnaire: a self-administered instrument for recently diagnosed patients. Multiple Sclerosis Journal, 16(1), 100-11.[DOI:10.1177/1352458509352865] [PMID]

Glanz, K., Maskarinec, G., \& Carlin, L. (2005). Ethnicity, sense of coherence, and tobacco use among adolescents. Annals of Behavioral Medicine, 29(3), 192-9. [DOI:10.1207/ s15324796abm2903_5] [PMID]

Hagh, R. F., Kakavand, A. R., Borjali, A., \& Bermas, H. (2011). Resiliency and life quality in mothers of children with mental retardation. Journal of Health Psychology, 1(1), 177-87. https:// www.sid.ir/en/journal/ViewPaper.aspx?ID=360993

Hassmen, P., Koivula, N., \& Uutela, A. (2000). Physical exercise and psychological well-being: A population study in Finland. Preventive Medicine, 30(1), 17-25. [DOI:10.1006/ pmed.1999.0597] [PMID]

Haussleiter, I. S., Brüne, M., \& Juckel, G. (2009). Psychopathology in multiple sclerosis: Diagnosis, prevalence and treatment. Therapeutic advances in neurological disorders, 2(1), 13-29. [DOI:10.1177/1756285608100325] [PMID] [PMCID]

Hazhir, F., Ahadi, H., Pourshahbaz, A., Rezaei, M. (2012). The effectiveness of cognitive-behavior therapy on illness representations of multiple-sclerosis and improving their emotional states. Journal of Kermanshah University of Medical Sciences, 15(6), 415-428. https://sites.kowsarpub.com/jkums/ articles/78893.html

Hulley SB, Cummings SR, Browner WS, Grady DG, \& Newman TB. (2013). Designing clinical research : an epidemiologic approach. (3th ed. ed.). Philadelphia,: PA: Lippincott Williams \& Wilkins.

Izadi, S., Nikseresht, A. R., Poursadeghfard, M., Borhanihaghighi, A., \& Heydari, S. T. (2015). Prevalence and incidence of multiple sclerosis in Fars province, Southern Iran Iranian Journal of Medical Sciences, 40(5), 390. [PMCID] [PMID]

Karimy, M., Abedi, A., Amin-Shokravi, F., \& Tavafian, S. S. (2013). Preventing hiv transmission among the opiate-dependent population in zarandieh: Evaluation of the hbmbased educational programs. Health Education \& Health Promotion, 1(1), 21-31. https://hehp.modares.ac.ir/article5-3781-en.pdf

Koch, J. (2002). The role of exercise in the African-American woman with type 2 diabetes mellitus: Application of the health belief model. Journal of the American Academy of Nurse Practitioners, 14(3), 26-30. [DOI:10.1111/j.1745-7599.2002. tb00103.x] [PMID]

Luthar, S. S., Cicchetti, D., \& Becker, B. (2000). The construct of resilience: A critical evaluation. Development and Psychopathology, 12(4), 857-85. [DOI:10.1017/S0954579400004156] [PMID] [PMCID]
Ma, L. C., Chang, H. J., Liu, Y. M., Hsieh, H. L., Lo, L., Lin, M. Y., \& Lu, K. C. (2013). The relationship between healthpromoting behaviors and resilience in patients with chronic kidney disease. The Scientific World Journal, 2013. [DOI:10.1155/2013/124973] [PMID] [PMCID]

Ma, L. C., Chang, H. J., Liu, Y. M., Hsieh, H. L., Lo, L., Lin, M. Y., \& Lu, K. C. (2013). The relationship between healthpromoting behaviors and resilience in patients with chronic kidney disease. The Scientific World Journal, 2013. [DOI:10.1155/2013/124973] [PMID] [PMCID]

Madani, H., Navipour, H., \& Rouzbayani, P. (2008). Relations between self-esteem and applying coping mechanism and self-care program in Multiple Sclerosis (MS) patients. Journal of Ilam University of Medical Sciences, 15(4), 31-41. https:/ www.sid.ir/en/journal/ViewPaper.aspx?ID=108782

Masoudi, R., Mohammadi, E., Nabavi, S. M., \& Ahmadi, F (2008). The effect of Orem based self-care program on physical quality of life in multiple sclerosis patients. Journal of Shahrekord Uuniversity of Medical Sciences, 10(2), 9-21. http://journal.skums.ac.ir/article-1-5-fa.htm

Mazaheri, M., Fanian, N., \& Zargham-Boroujeni, A. (2011). Experiences of patients with multiple sclerosis from group counseling. Iranian Journal of Nursing and Midwifery Research 16(2), 181. [PMCID] [PMID]

Mohammadzadeh, J., \& Sayehmiri, K. (2016). [Standardization of social support scale (MOS) of adults who have chronic diseases in Ilam, 2015 (Persian)]. Scientific Journal of Ilam University of Medical Sciences, 23(7), 69-77. [http://sjimu.medilam. ac.ir/article-1-2483-fa.html]

MorowatiSharifabad, M. A., Momeni, Z., Eslami, M. H., DehghaniTafti, A., \& Hakimzadeh, A. (2016). [Study of Factors Associated with Self-Care bhaviors in patients with Multiplesclerosis in Yazd City based on health belief model (Persian)]. Tolooebehdasht, 15(2), 82-93. http://tbj.ssu.ac.ir/ article-1-2189-fa.html

Mousavizadeh, A., Dastoorpoor, M., Naimi, E., \& Dohrabpour K. (2018). Time-trend analysis and developing a forecasting model for the prevalence of multiple sclerosis in Kohgiluyeh and Boyer-Ahmad Province, Southwest of Iran. Public Health 154, 14-23. [DOI:10.1016/j.puhe.2017.10.003] [PMID]

Naroie, S., Naji, S. A., Abdeyazdan, G. H., \& Dadkani, E. (2012) Effect of applying self-care orem model on quality of life in the patient under hemodialysis. Zahedan Journal of Research in Medical Sciences, 14(1), 8-12. https://sites.kowsarpub.com/ zjrms/articles/93608.html

O'Brien, M. T. (1993). Multiple sclerosis: the relationship among self-esteem, social support, and coping behavior. Applied Nursing Research, 6(2), 54-63. [DOI:10.1016/S08971897(05)80103-X]

Pender, N. J., Murdaugh, C. L., \& Parsons, M. A. (2006). Health promotion in nursing practice. New Jersey: Prentice Hall https:// books.google.com/books?id=jVJqAAAAMAAJ\&q

Polsingchan S. (2010). Health-promoting behaviors in Thai persons with chronic renal failure [PhD. thesis]. Texas: The University of Texas at Austin. http:// citeseerx.ist.psu.edu/viewdoc/down load?doi=10.1.1.834.1195\&rep=rep1\&type=pdf

Rigby, S., Domenech, C., Thornton, E., Tedman, S., \& Young, C. (2003). Development and validation of a self-efficacy meas- 
ure for people with multiple sclerosis: The Multiple Sclerosis Self-efficacy Scale. Multiple Sclerosis Journal, 9(1), 73-81. [DOI:10.1191/1352458503ms870oa] [PMID]

Rosenberg, M. (1965). Rosenberg Self-Esteem Scale (RSE). Acceptance and commitment therapy. Measures Package, 61, 52. [DOI:10.1037/t01038-000]

Safarpour Y. (2014). [Evaluation of knowledge of patients with Multiple Sclerosis in case Multiple Sclerosis patients referring to Imam Hossein Hospital in 2014 (Persian)]. [MD. thesis]. Tehran: Shahid Beheshti University of Medical sciences.

Salahshoori, A., Harooni, J., Salahshouri, S., Hassanzadeh, A., Mostafavi, F., \& Molaei, M. (2015). Investigation on association between self-efficacy, perceived barriers and social supports with health promoting behaviors in elderly in Dena city. Health System Research, 11(1), 30-42. http://hsr.mui.ac.ir/ article-1-763-fa.html

Scherer, Y. K., \& Bruce, S. (2001). Knowledge, attitudes, and self-efficacy and compliance with medical regimen, number of emergency department visits, and hospitalizations in adults with asthma. Heart $\mathcal{E}$ Lung, 30(4), 250-7. [DOI:10.1067/ mhl.2001.116013] [PMID]

Sedaghat, F., Jessri, M., Behrooz, M., Mirghotbi, M., \& Rashidkhani, B. (2016). Mediterranean diet adherence and risk of multiple sclerosis: A case-control study. Asia Pacific Journal of Clinical Nutrition, 25(2), 377-84. http://apjcn.nhri.org.tw/ server/APJCN/25/2/377.pdf

Simmons,S.J.(1990). Thehealth-promoting self-caresystemmodel: Directions for nursing research and practice. Journal of $A d-$ vanced Nursing, 15(10), 1162-6.[DOI:10.1111/j.1365-2648.1990. tb01708.x] [PMID]

Simmons,S.(1990b). Thehealth-promotingSelf-caresystemModel: Directions for nursing researh and practice. Journal of Advanced Nursing, 15(10), 1162-6. [DOI:10.1111/j.1365-2648.1990. tb01708.x] [PMID]

Sinclair, V. G., \& Scroggie, J. (2005). Effects of a cognitive-behavioral program for women with multiple sclerosis. Journal of Neuroscience Nursing, 37(5), 249-57. [DOI:10.1097/01376517200510000-00004] [PMID]

Stewart, A. L., Hays, R. D., \& Ware, J. E. (1988). The MOS short-form general health survey: Reliability and validity in a patient population. Medical Care, 26(7), 724-35. [DOI:10.1097/00005650-198807000-00007] [PMID]

Tabatabaei, S. V. A., Ardabili, H. E., Haghdoost, A. A., Dastoorpoor, M., Nakhaee, N., \& Shams, M. (2017). Factors affecting physical activity behavior among women in Kerman Based on the Theory of Planned Behavior (TPB). Iranian Red Crescent Medical Journal, 19(10). [DOI:10.5812/ircmj.14057]

Tanhaye Reshvanlo, F., \& Soleimanian, A. (2012). [Psychometric examination of Multiple Sclerosis Self-Efficacy Scale (Persian)]. The Journal of Applied Behavioral Science, 12(1), 9-18.

Valizadeh R, Sohrabnejad S, Mehraban S, \& Ahmadbokani S. (2014). [Effectiveness of cognitive-behavioral based stress management training on depression of MS female patients (Persian)]. Scientific Journal of Ilam University of Medical Sciences, 23(5), 91-8. https://www.sid.ir/en/Journal/ViewPaper. aspx?ID=482595
Von Bothmer, M. I., \& Fridlund, B. (2005). Gender differences in health habits and in motivation for a healthy lifestyle among Swedish university students. Nursing and Health Sciences, 7(2), 107-18. [DOI:10.1111/j.1442-2018.2005.00227.x] [PMID]

Wainwright, N. W., Surtees, P. G., Welch, A. A., Luben, R. N., Khaw, K. T., \& Bingham, S. A. (2007). Healthy lifestyle choices: could sense of coherence aid health promotion? Journal of Epidemiology \& Community Health, 61(10), 871-6. [DOI:10.1136/ jech.2006.056275] [PMID] [PMCID]

Walker, S., Sechrist, K., \& Pender, N. (1995). The health-promoting lifestyle profile II.

Wendling, S., \& Beadle, V. (2015). The relationship between self-efficacy and diabetic foot self-care. Journal of Clinical $\mathcal{E}$ Translational Endocrinology, 2(1), 37-41. [DOI:10.1016/j. jcte.2015.01.001] [PMID] [PMCID]

While, A., Ullman, R., \& Forbes, A. (2007). Development and validation of a learning needs assessment scale: A continuing professional education tool for multiple sclerosis specialist nurses. Journal of Clinical Nursing, 16, 1099-8. [DOI:10.1111/ j.1365-2702.2007.01693.x] [PMID]

Wu, S. F. V., Courtney, M., Edwards, H., McDowell, J., Shortridge-Baggett, L. M., \& Chang, P. J. (2007). Self-efficacy, outcome expectations, and self-care behaviour in people with type 2 diabetes in Taiwan. Journal of Clinical Nursing, 16(11c), 250-7. [DOI:10.1111/j.1365-2702.2006.01930.x] [PMID]

Yazdani, M. H., \& Montazer, F. (2017). [Analysis of indicators of health status in provinces and ten regions of Iran (Persian)] Health and Development Journal, 6(4), 290-301. http://jhad. kmu.ac.ir/article-1-419-fa.html

Pan, S. Y., Cameron, C., Desmeules, M., Morrison, H., Craig, C. L., \& Jiang, X. (2009). Individual, social, environmental, and physical environmental correlates with physical activity among Canadians: A cross-sectional study. BMC Pub Health, 9:21. [DOI:10.1186/1471-2458-9-21] [PMID] [PMCID] 
This Page Intentionally Left Blank 